\title{
Kinetic behavior of soluble Pectinex Ultra SP-L converting sucrose into fructo-oligosaccharides in batch and continuous fashion
}

\author{
ZOLTÁN KOVÁCS ${ }^{1 *}$ ㅁ, JURAJ ŠTEVEK ${ }^{2}$, MIROSLAV FIKAR $^{2}$ and \\ PETER CZERMAK ${ }^{3,4}$
}

${ }^{1}$ Department of Food Engineering, Szent István University, Budapest, Hungary

${ }^{2}$ Department of Information Engineering and Process Control FCFT, Slovak University of Technology, Bratislava, Slovakia

${ }^{3}$ Institute of Bioprocess Engineering and Pharmaceutical Technology, University of Applied Sciences Mittelhessen, Giessen, Germany

${ }^{4}$ Fraunhofer Institute IME-Bioresources, Giessen, Germany

\section{ORIGINAL RESEARCH PAPER}

Received: August 18, 2020 • Accepted: November 20, 2020

Published online: December 09, 2020

(C) 2020 The Author(s)

\section{ABSTRACT}

The enzymatic conversion of sucrose to fructo-oligosaccharides (FOS) catalyzed by Pectinex Ultra SP-L, a commercial enzyme preparation from Aspergillus aculeatus, under free condition was studied. A mathematical analysis of the transfructosylation reactions was carried out to estimate the dynamic and steady-state performance of an enzyme membrane reactor (EMR) and to compare the continuous production scheme with the traditional batch process realized in stirred-tank reactor (STR). Kinetic parameters were identified simultaneously from a series of progress curves obtained from STR and EMR experimental runs. Model estimates appeared to fit well to experimental observations under the studied reaction conditions. Although conventional batch reactor outperforms EMR in terms of conversion, EMR compares favorably regarding productivity. The on-site industrial implementation of this

\footnotetext{
* Corresponding author. E-mail: kovacs.zoltan@etk.szie.hu
} 
technology might be attractive for food manufacturers aiming at utilizing a value-added sweetener mixture with prebiotic properties.

\section{KEYWORDS}

fructo-oligosaccharide, fructosyltransferase, enzyme membrane reactor, prebiotics, Pectinex Ultra SP-L

\section{INTRODUCTION}

Fructooligosaccharides (FOS) are considered to be physiologically favorable food ingredients that may improve the balance of intestinal microflora (Sangeetha et al., 2005). A wide variety of health benefits has been claimed in connection with the addition of such prebiotics to food products (Picazo et al., 2019). FOS can be thought of as low molecular weight, non-viscous, water-soluble dietary fibers. Short-chain FOS can be produced by enzymatic synthesis from sucrose using fructosyltransferase (FTase). The reaction is commonly performed at high initial sucrose concentration (over $300 \mathrm{gL}^{-1}$ ) in order to shift enzyme activity from hydrolysis of sucrose towards transfructosylation. The conversion is a complex process that involves a series of consecutive and parallel reactions in which the substrate goes through several intermediate stages. The resulting compounds are FOS, including 1-kestose $\left(\mathrm{GF}_{2}\right)$, nystose $\left(\mathrm{GF}_{3}\right)$ and fructofuranosyl nystose $\left(\mathrm{GF}_{4}\right)$, non-reacted sucrose $(\mathrm{GF})$, and by-product glucose $(\mathrm{G})$. The byproduct glucose has been reported to be the main factor lowering yield during FOS synthesis (Burghardt et al., 2019).

Despite the complexity of the reaction scheme, several mathematical models have been proposed and successfully implemented to describe the kinetics of enzymes from Aureobasidium sp. (Jung et al., 1989), Saccharomyces sp. (Khandekar et al., 2014), Rhodotorula sp. (Alvarado and Maugeri, 2007), Trichoderma sp. (Vega and Zuniga-Hansen, 2014) and Aspergillus sp. (Duan et al., 1994; Guio et al., 2012; Kashyap et al., 2015; Nishizawa et al., 2001; Rocha et al., 2009).

FOS can be produced by whole cells or (partially) purified enzymes. Continuous production of FOS in packed bed reactors utilizing immobilized cells entrapped in calcium alginate gel has been commercially realized (Yun, 1996). Other microbiological production techniques have been reviewed in (Sangeetha et al., 2005).

Enzymatic FOS synthesis can be realized using systems with soluble enzymes or immobilized enzymes. Recent studies have reported FOS production using immobilized enzymes on various carriers such as ceramic membranes (Nishizawa et al., 2000), epoxy-activated acrylic beads (Tanriseven and Aslan, 2005), chitosan-coated magnetic nanoparticles (Chen et al., 2014), and on epoxy-activated polymethacrylate carriers (Ghazi et al., 2006). It has been pointed out that immobilization of FTase is only justified when the biocatalysts are expensive or have reduced stability under process conditions (Vega-Paulino and Zúniga-Hansen, 2012).

It is known that many low-cost commercial enzyme preparations have high levels of FTase activity. Among them, Pectinex Ultra SP-L (Novozyme A/S, Denmark) has been previously reported to have a superior transfer to hydrolysis activity (Hang and Woodams, 1996). Furthermore, a notable thermal and pH stability of Pectinex Ultra SP-L has been found by Ghazi 
et al. (Ghazi et al., 2007). The high concentration of saccharides present in the reaction media has been identified as one of the reasons for protein stabilization, and in particular, associated with a protective effect on transfructosylation activity (Vega-Paulino and Zúniga-Hansen, 2012).

In view of the above reasons, the employment of soluble enzymes may be considered as an alternative to immobilized enzymes. Although stirred tank reactors (STR) offer a simple design and easy-to-operate production scheme, one of the drawbacks of STR is that the biocatalysts have to be inactivated after the reaction and then removed from the resulting FOS-containing solution prior to the application of the reaction product in food formulas. In contrast, enzyme membrane reactors (EMR) utilizing free enzymes enable both the biotransformation and the recovery of biocatalysts in a single-step. We have previously shown that EMR can be employed for FOS production using molasses as substrate (Rehman et al., 2016) and real-time monitoring of the continuous production scheme may be achieved by UV spectrophotometry combined with chemometrics tools (Erdös et al., 2018).

The FOS production by Pectinex Ultra SP-L in STR was experimentally investigated by Kashyap et al. (2015), and optimal reaction conditions such as initial substrate concentration, temperature and $\mathrm{pH}$ were determined. However, previous modeling effort on the transfructosylation action of this enzyme preparation has been restricted to a simplistic kinetic mechanism that does not allow the prediction of individual FOS fractions, and analysis was limited to batch configuration (Kashyap et al., 2015).

The purpose of this communication is to provide a mathematical description of the biocatalytic behavior of Pectinex Ultra SP-L. We formulate kinetic models that describe FOS production in both STR and EMR, derive the kinetic parameters on the basis of observed experimental data, and compare the catalytic performance of such systems in terms of substrate conversion and productivity.

\section{KINETIC MODELING}

In this section we introduce a kinetic model that relates observations to operational settings via parameters. We adopt the reaction scheme proposed by Nishizawa et al. (2001). Our goal is to obtain estimates of model parameters and the subsequent use of the models to make predictions for transfructosylation reactions in STR and EMR configurations.

\section{Batch operation}

According to Nishizawa et al. (2001), the reaction mechanisms involved in the production of FOS are given by

$$
\begin{gathered}
\mathrm{GF}+\mathrm{GF} \stackrel{r_{1}}{\rightarrow} \mathrm{GF}_{2}+\mathrm{G}, \\
\mathrm{GF}_{2}+\mathrm{GF}_{2} \stackrel{r_{2}}{\longrightarrow} \mathrm{GF}_{3}+\mathrm{GF}, \\
\mathrm{GF}_{3}+\mathrm{GF}_{3} \stackrel{r_{3}}{\rightarrow} \mathrm{GF}_{4}+\mathrm{GF}_{2}, \\
\mathrm{GF}+\mathrm{GF}_{2} \stackrel{r_{4}}{\rightarrow} \mathrm{GF}_{3}+\mathrm{G}, \\
\mathrm{GF}+\mathrm{GF}_{3} \stackrel{r_{5}}{\rightarrow} \mathrm{GF}_{4}+\mathrm{G},
\end{gathered}
$$




$$
\mathrm{GF}_{2}+\mathrm{GF}_{3} \stackrel{r_{G}}{\rightarrow} \mathrm{GF}_{4}+\mathrm{GF}
$$

where $[\mathrm{G}],[\mathrm{GF}],\left[\mathrm{GF}_{2}\right],\left[\mathrm{GF}_{3}\right]$ and $\left[\mathrm{GF}_{4}\right]$ are the concentration of glucose, sucrose, $\mathrm{GF}_{2}, \mathrm{GF}_{3}$ and $\mathrm{GF}_{4}$, respectively.

The mass balance equations on the compounds involved in the reaction scheme (1a-1f) in a for stirred-tank reactor are derived as follows:

$$
\begin{gathered}
\frac{d[\mathrm{G}]}{d t}=r_{1}+r_{4}+r_{5}, \\
\frac{d[\mathrm{GF}]}{d t}=-2 r_{1}+r_{2}-r_{4}-r_{5}+r_{6}, \\
\frac{d\left[\mathrm{GF}_{2}\right]}{d t}=r_{1}-2 r_{2}+r_{3}-r_{4}-r_{6}, \\
\frac{d\left[\mathrm{GF}_{3}\right]}{d t}=r_{2}-2 r_{3}+r_{4}-r_{5}-r_{6}, \\
\frac{d\left[\mathrm{GF}_{4}\right]}{d t}=r_{3}+r_{5}+r_{6},
\end{gathered}
$$

Equation (2) represent the mass balance model.

Rate equations for Eqs. (1a), (1b) and (1c) are given as follows:

$$
\begin{gathered}
r_{1}=\frac{V_{\mathrm{m}, \mathrm{GF}}[\mathrm{GF}]^{2}}{K_{\mathrm{m} 1, \mathrm{GF}} K_{\mathrm{m} 2, \mathrm{GF}}+K_{\mathrm{m} 2, \mathrm{GF}}[\mathrm{GF}]+[\mathrm{GF}]^{2}+K_{\mathrm{m} 2, \mathrm{GF}}[\mathrm{GF}][\mathrm{G}] / K_{\mathrm{i}, \mathrm{in}}+K_{\mathrm{m} 1, \mathrm{GF}} K_{m 2, \mathrm{GF}}[\mathrm{GF}] / K_{i, n}} \\
K_{\mathrm{m} 1, \mathrm{GF}}=\frac{[\mathrm{E}][\mathrm{GF}]}{[\mathrm{EGF}]} \\
K_{\mathrm{m} 2, \mathrm{GF}}=\frac{[\mathrm{EGF}][\mathrm{GF}]}{[\mathrm{EGFGF}]} \\
K_{i, n}=\frac{[\mathrm{EGF}][\mathrm{G}]}{\left[\mathrm{EGGF}^{2}\right.} \\
V_{\mathrm{m}, \mathrm{GF}_{2}\left[\mathrm{GF}_{2}\right]^{2}} \\
r_{2}=\frac{\left[\mathrm{E}^{2}\left[\mathrm{GF}_{2}\right]\right.}{\left[\mathrm{EGF}_{2}\right]} \\
K_{\mathrm{m} 1, \mathrm{GF}_{2}} K_{\mathrm{m} 2, \mathrm{GF}_{2}}+\frac{K_{\mathrm{m}_{2}, \mathrm{GF}_{2}}\left[\mathrm{GF}_{2}\right]+\left[\mathrm{GF}_{2}\right]^{2}}{\left[\mathrm{EGF}_{2}\right]\left[\mathrm{GF}_{2}\right]} \\
K_{\mathrm{m} 2, \mathrm{GF}_{2}}
\end{gathered}
$$




$$
\begin{gathered}
r_{3}=\frac{V_{\mathrm{m}, \mathrm{GF}_{3}}\left[\mathrm{GF}_{3}\right]^{2}}{K_{\mathrm{m} 1, \mathrm{GF}_{3}} K_{\mathrm{m} 2, \mathrm{GF}_{3}}+K_{\mathrm{m}_{2}, \mathrm{GF}_{3}}\left[\mathrm{GF}_{3}\right]+\left[\mathrm{GF}_{3}\right]^{2}}, \\
K_{\mathrm{m} 1, \mathrm{GF}_{3}}=\frac{[\mathrm{E}]\left[\mathrm{GF}_{3}\right]}{\left[\mathrm{EGF}_{3}\right]}, \\
K_{\mathrm{m} 2, \mathrm{GF}_{3}}=\frac{\left[\mathrm{EGF}_{3}\right]\left[\mathrm{GF}_{3}\right]}{\left[\mathrm{EGF}_{3} \mathrm{GF}_{3}\right]}
\end{gathered}
$$

where $[\mathrm{E}],[\mathrm{EGF}],[\mathrm{EGFGF}],\left[\mathrm{EGF}_{2}\right],\left[\mathrm{EGF}_{2} \mathrm{GF}_{2}\right],\left[\mathrm{EGF}_{3}\right]$ and $\left[\mathrm{EGF}_{3} \mathrm{GF}_{3}\right]$ are concentrations of enzyme, enzyme-sucrose complex, enzyme-sucrose-sucrose complex, enzyme- $\mathrm{GF}_{2}$ complex, enzyme- $\mathrm{GF}_{2}-\mathrm{GF}_{2}$ complex, enzyme- $\mathrm{GF}_{3}$ complex and enzyme- $\mathrm{GF}_{3}-\mathrm{GF}_{3}$ complex, respectively. $V_{\mathrm{m}}$ and $K_{\mathrm{m}}$ are maximum transfructosylation rate and dissociation constants. $K_{\mathrm{m} 1}$ denotes dissociation constant for enzyme-substrate complex, $K_{\mathrm{m} 2}$ represents dissociation constant for enzyme-substrate-substrate complex, and $K_{\mathrm{i}, \mathrm{n}}$ denotes non-competitive inhibitory constant. Rate equations for Eqs. (1d-1f) are given as follows:

$$
\begin{aligned}
& r_{4}=\frac{V_{\mathrm{m} 4}[\mathrm{GF}]\left[\mathrm{GF}_{2}\right]}{K_{\mathrm{m} 2, \mathrm{GF}=\mathrm{GF}_{2}}\left(K_{\mathrm{m} 1, \mathrm{GF}}+[\mathrm{GF}]\right)+\left[\mathrm{GF}_{2}\right]\left(\mathrm{K}_{\mathrm{m} 2, \mathrm{GF}_{2}-\mathrm{GF}}+[\mathrm{GF}]\right)} \\
& K_{\mathrm{m} 2, \mathrm{GF}-\mathrm{GF}_{2}}=\frac{[\mathrm{EGF}]\left[\mathrm{GF}_{2}\right]}{\left[\mathrm{EGFGF}_{2}\right]}, \\
& K_{\mathrm{m} 2, \mathrm{GF}_{2}-\mathrm{GF}}=\frac{\left[\mathrm{EGF}_{2}\right][\mathrm{GF}]}{\left[\mathrm{EGF}_{2} \mathrm{GF}\right]}, \\
& r_{5}=\frac{V_{\mathrm{m} 5}[\mathrm{GF}]\left[\mathrm{GF}_{3}\right]}{K_{\mathrm{m} 2, \mathrm{GF}-\mathrm{GF}_{3}}\left(K_{\mathrm{m} 1, \mathrm{GF}}+[\mathrm{GF}]\right)+\left[\mathrm{GF}_{3}\right]\left(K_{\mathrm{m} 2, \mathrm{GF}_{3}-\mathrm{GF}}+[\mathrm{GF}]\right)}, \\
& K_{\mathrm{m} 2, \mathrm{GF}-\mathrm{GF}_{3}}=\frac{[\mathrm{EGF}]\left[\mathrm{GF}_{3}\right]}{\left[\mathrm{EGFGF}_{3}\right]}, \\
& K_{\mathrm{m} 2, \mathrm{GF}_{3}-\mathrm{GF}}=\frac{\left[\mathrm{EGF}_{3}\right][\mathrm{GF}]}{\left[\mathrm{EGF}_{3} \mathrm{GF}\right]} \text {, }
\end{aligned}
$$

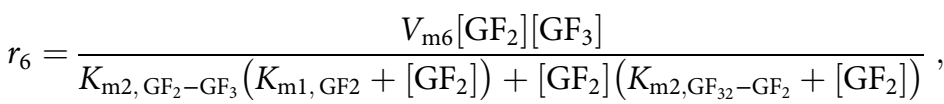

$$
\begin{aligned}
& K_{\mathrm{m} 2, \mathrm{GF}_{2}-\mathrm{GF}_{3}}=\frac{\left[\mathrm{EGF}_{2}\right]\left[\mathrm{GF}_{3}\right]}{\left[\mathrm{EGF}_{2} \mathrm{GF}_{3}\right]}, \\
& K_{\mathrm{m} 2, \mathrm{GF}_{3}-\mathrm{GF}_{2}}=\frac{\left[\mathrm{EGF}_{3}\right]\left[\mathrm{GF}_{2}\right]}{\left[\mathrm{EGF}_{3} \mathrm{GF}_{2}\right]}
\end{aligned}
$$

where $\left[\mathrm{EGFGF}_{2}\right],\left[\mathrm{EGF}_{2} \mathrm{GF}\right],\left[\mathrm{EGFGF}_{3}\right],\left[\mathrm{EGF}_{3} \mathrm{GF}\right],\left[\mathrm{EGF}_{2} \mathrm{GF}_{3}\right]$ and $\left[\mathrm{EGF}_{3} \mathrm{GF}_{2}\right]$ are concentrations of enzyme-sucrose- $\mathrm{GF}_{2}$ complex, enzyme- $\mathrm{GF}_{2}$-sucrose complex, enzyme-sucrose- $\mathrm{GF}_{3}$ 
complex, enzyme- $\mathrm{GF}_{3}$-sucrose complex, enzyme- $\mathrm{GF}_{2}-\mathrm{GF}_{2}$ complex and enzyme- $\mathrm{GF}_{3}-\mathrm{GF}_{2}$ complex, respectively.

\section{Continuous operation}

The mass balance model (Eqs. (2)) may be modified to describe the continuous production in EMR as follows:

$$
\begin{gathered}
\frac{d[\mathrm{G}]}{d t}=-\frac{[\mathrm{G}]}{\tau}+r_{1}+r_{4}+r_{5}, \\
\frac{d[\mathrm{GF}]}{d t}=\frac{S-[\mathrm{GF}]}{\tau}-2 r_{1}+r_{2}-r_{4}-r_{5}+r_{6}, \\
\frac{d\left[\mathrm{GF}_{2}\right]}{d t}=-\frac{\left[\mathrm{GF}_{2}\right]}{\tau}+r_{1}-2 r_{2}+r_{3}-r_{4}-r_{6}, \\
\frac{d\left[\mathrm{GF}_{3}\right]}{d t}=-\frac{\left[\mathrm{GF}_{3}\right]}{\tau}+r_{2}-2 r_{3}+r_{4}-r_{5}-r_{6}, \\
\frac{d\left[\mathrm{GF}_{4}\right]}{d t}=-\frac{\left[\mathrm{GF}_{4}\right]}{\tau}+r_{3}+r_{5}+r_{6},
\end{gathered}
$$

where $S$ is the concentration of sucrose in the feed continuously supplied into the reactor and $\tau$ is the hydraulic residence time calculated as the ratio of reactor volume to stationary permeate flow.

\section{MATERIALS AND METHODS}

\section{Materials}

Food-grade sucrose manufactured by Pfeifer and Lanngen KG (Köln, Germany) was purchased from a local food store. Pectinex Ultra SP-L, a commercial enzyme preparation from Aspergillus aculeatus, was supplied by Novozyme A/S (Bagsvaerd, Denmark). The activity of the crude enzyme extract used in this study was $95 \mathrm{Ug}^{-1}$ determined by the Ftase activity assay as described in Section "Enzyme activity assay". A ceramic tubular UF membrane consisting of 19 feed channels was purchased from Atech Innovation GmbH (Gladbeck, Germany). The specifications of the membrane module are summarized in Fig. 1.

\section{Enzyme activity assay}

Sucrose (40 g) in citrate/phosphate buffer ( $52.5 \mathrm{~g}, \mathrm{pH}$ 5.4) was incubated with enzyme preparation $(7.5 \mathrm{~g})$ at $50{ }^{\circ} \mathrm{C}$ for $1 \mathrm{~h}$. The reaction was stopped by heat treatment at $95{ }^{\circ} \mathrm{C}$ for $20 \mathrm{~min}$. The concentration of free glucose was determined by HPLC. One unit of FTase was defined as the amount of crude enzyme liberating $1 \mu \mathrm{mol}$ of glucose per minute under the above assay conditions.

\section{Batch procedure}

FOS was produced in batch fashion in a stirred-tank reactor (STR). The reaction liquid was prepared using a dosage of $7.5 \mathrm{~g} / 100 \mathrm{~g}$ of crude enzyme preparation and $40 \mathrm{~g} / 100 \mathrm{~g}$ food-grade 


\begin{tabular}{ll}
\hline Manufacturer & Atech Innovation GmbH, Germany \\
Type & $19 / 3.3$ \\
Support material & $\alpha-\mathrm{Al}_{2} \mathrm{O}_{3}$ \\
Active layer material & $\mathrm{TiO}_{2}$ \\
pH stability & $0 \mathrm{up}$ to 14 \\
Cut-off & $20 \mathrm{kD}$ \\
Length & $440 \mathrm{~mm}$ \\
Number of channels & 19 \\
Inner diameter & $3.3 \mathrm{~mm}$ \\
Outer diameter & $25.4 \mathrm{~mm}$ \\
Filtration area & $0.087 \mathrm{~m}^{2}$ \\
Cross-flow area & $1.625 \cdot 10^{-4} \mathrm{~m}^{2}$ \\
\hline
\end{tabular}

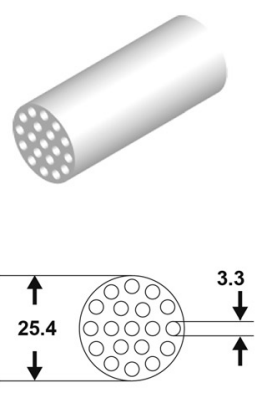

Fig. 1. Technical data and membrane geometry

sucrose. The $\mathrm{pH}$ was adjusted to 5.4 with citrate/phosphate buffer, the temperature was kept at $50 \pm 0.1{ }^{\circ} \mathrm{C}$, and the process liquid was gently stirred with a magnetic stirrer at $100 \mathrm{rpm}$. The experiment was performed in duplicate, samples taken from the reaction liquid were kept at 95 ${ }^{\circ} \mathrm{C}$ for 20 min for enzyme deactivation prior to HPLC analysis.

\section{Continuous production scheme}

FOS was produced in an EMR operating in continuous fashion. The EMR is composed of a continuous stirred tank reactor for catalysis and an external ultrafiltration (UF) module for enzyme retention. A schematic of the EMR set-up is shown in Fig. 2.

A 2L-reactor made of glass was placed on a Heidolph MR Hei-Standard hotplate magnetic stirrer equipped with a temperature control unit (Heidolph Instruments $\mathrm{GmbH} \& \mathrm{Co}$. KG, Schwabach, Germany). The reactor was initially filled with a certain amount of reaction liquid that consisted of $7.5 \mathrm{~g} / 100 \mathrm{~g}$ of crude enzyme preparation and $40 \mathrm{~g} / 100 \mathrm{~g}$ food-grade sucrose in citrate/phosphate buffer $(\mathrm{pH}=5.4 \pm 0.1)$. Its temperature was kept at $50 \pm 1{ }^{\circ} \mathrm{C}$. An Ismatec

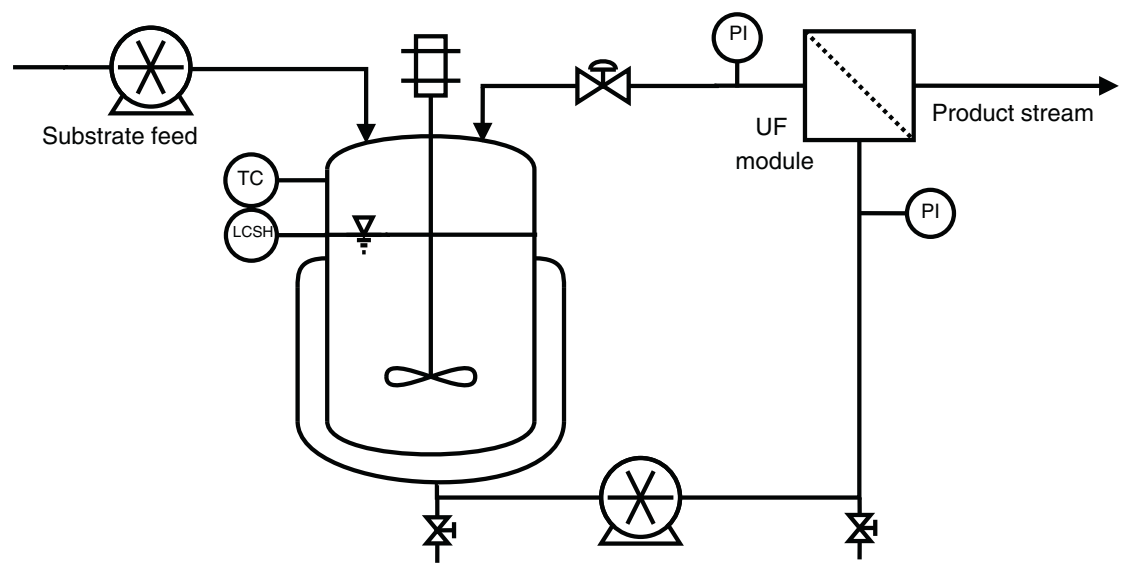

Fig. 2. Schematic diagram of the lab-scale enzyme membrane reactor 
MCP-Z gear pump (Cole-Parmer GmbH, Wertheim, Germany) was employed to circulate the process liquid through the UF module with a fixed cross-flow velocity of $0.42 \mathrm{~ms}^{-1}$. Taking into account the physical properties of the process liquid and the geometry of our membrane module, this cross-flow velocity corresponds to a Reynolds number of approx. 660. Experiments were conducted at various residence times. The residence time, $\tau$, that is the ratio of reaction volume to permeate flow, was varied between 36 and $102 \mathrm{~min}$. It was achieved by employing different amounts of reaction liquid $(0.5-1.5 \mathrm{~L})$ and adjusting the permeate flow with the transmembrane pressure. Three 8 -h process runs were carried out at $1.5 \mathrm{bar}$, and an additional run at 0.5 bar was conducted for $25 \mathrm{~h}$.

In all test runs, the permeate of the UF module (i.e. the enzyme-free product) was withdrawn from the reactor, and simultaneously, equal amount of fresh substrate was fed into the reactor. The feed solution also consisted of $40 \mathrm{~g} / 100 \mathrm{~g}$ food-grade sucrose in citrate/phosphate buffer at $\mathrm{pH} 5.4 \pm 0.1$ and $50 \pm 1{ }^{\circ} \mathrm{C}$. Automation of this process was done by monitoring the weight of the reactor with a balance, and controlling the speed of the feed pump accordingly by a LabManager process control system (HiTec Zang $\mathrm{GmbH}$, Herzogenrath, Germany) to ensure a constant volume in the reactor. We employed a constant pressure set point control, while the permeate flow was uncontrolled. The trans-membrane pressure was adjusted with a precision valve at the retentate side and kept constant along the operation time. Samples were taken from the product (permeate) stream for determination of carbohydrates by HPLC.

\section{Terminology}

Definitions used in this study:

- Relative mass fraction: the ratio of the mass of a substance to the total mass of carbohydrates present in the solution.

- Relative mass percentage: the relative mass fraction multiplied by $100 \%$.

- Residence time $(\tau)$ : the reactor volume divided by the volumetric flow rate entering the reactor.

- Conversion (C): the amount of sucrose consumed divided by the amount of sucrose fed into the reactor.

- Productivity (P): the total quantity of FOS synthesized by $1 \mathrm{~g}$ of crude enzyme preparation per hour.

\section{Analytical methods}

Quantification of saccharides were performed by high performance liquid chromatography (1500 Series HPLC system, JASCO Inc., Japan) using an Aminex HPX-42C (Bio-Rad Laboratories, Inc., US) column for separation. Sugars were eluted with Milli-QTM water at a flow-rate of $0.2 \mathrm{~mL} \mathrm{~min}-1$ at $75{ }^{\circ} \mathrm{C}$ and detected with a Jasco 830 -RI refractive index detector. Identification of oligosaccharides, and determination of their concentrations, were conducted based on comparisons with reference solutions of the compounds in question (Fructooligosaccharides Set for HPLC, Cat. No. 298-64101, Wako Pure Chemical Industries, Ltd., Osaka, Japan).

\section{Parameter estimation of kinetic parameters}

The estimation of the kinetic parameters has to take into account nonlinear differential equations of the model (2) (batch) or (5) (continuous). The model can in general form be written as 


$$
\begin{aligned}
& \frac{d y(t, \theta)}{d t}=f(y(t, \theta), S(t), \theta) \\
& y\left(t_{0}\right)=y_{0}(\theta), \quad t \in\left[t_{0}, t_{f}\right]
\end{aligned}
$$

where $y$ comprises measured concentrations, the parameter vector $\theta$ consists of unknown process parameters and $t_{0}, t_{f}$ denote initial and final time of an experiment, respectively.

We can assume that the experimental data is collected in discrete time points $t_{i} \epsilon\left[t_{0}, t_{f}\right]$. The quantity $y_{i j k}$ denotes the model prediction at time $t_{i}$ of the $j$-th concentration in the $k$-th experiment.

We distinguish the model value $y_{i j k}$ and observed data $\tilde{y}_{i j k}$.

The estimation task can be formulated as the minimization of the weighted least squares cost (Draper and Smith, 2014; Gábor and Banga, 2015)

$$
Q_{L S}(\theta)=\sum_{k=1} \sum_{j=1} \sum_{i=1}\left(\frac{y_{i j k}(\theta)-\tilde{y}_{i j k}}{\sigma_{i j k}}\right)^{2}
$$

where the weighting factors $\sigma_{i j k}$ can be chosen to normalise the data. The nonlinear least-squares optimization problem is then formulated as

$$
\begin{aligned}
& \min _{\theta} Q_{l s}(\theta) \\
& \text { s.t. : } \theta_{\min } \leq \theta \leq \theta_{\max } \\
& \frac{d y(t, \theta)}{d t}=f(y(t, \theta), S(t), \theta) \\
& y\left(t_{0}\right)=y_{0}(\theta), \quad t \in\left[t_{0}, t_{f}\right]
\end{aligned}
$$

As the model equations are nonlinear, there is no guarantee that the optimization solver will find the global minimum of the problem. Therefore, multi-start method will be used (Gábor and Banga, 2015). Here, several optimization runs are performed initialized differently and the best solution is then picked. If the number of runs is sufficiently high, the probability of finding the global minimum will increase.

\section{RESULTS AND DISCUSSION}

\section{Parameter identification}

The kinetic parameters of the model proposed by Nishizawa et al. (2001) were identified from all experimental data available (4 independent runs in EMR and 2 independent STR tests) by using global search algorithms described in Section "Parameter estimation of kinetic parameters". We employed differential equation solver CVODES from SUNDIALS suite (Hindmarsh et al., 2005) and interior-point optimization method. The number of optimization runs was fixed to 500 .

Best-fitting values of kinetic parameters listed in Eqs. (3) and (4) are shown in Table 1 and 2, respectively.

In general, parameter estimation in such nonlinear dynamic models is known to be a challenging problem due to its nonconvexity and ill-conditioning. Therefore, it is important to 
Table 1. Estimated rate constants for Eqs. (3)

\begin{tabular}{lcccc}
\hline & $V_{\mathrm{m}}\left(\mu \mathrm{mol} \mathrm{L}^{-1} \mathrm{~min}^{-1}\right)$ & $K_{\mathrm{m} 1}\left(\mathrm{~mol} \mathrm{~L}^{-1}\right)$ & $K_{\mathrm{m} 2}\left(\mathrm{~mol} \mathrm{~L}^{-1}\right)$ & $K_{\mathrm{i}, \mathrm{n}}\left(\mathrm{mol} \mathrm{L}^{-1}\right)$ \\
\hline $\mathrm{GF}$ & 214.40 & 3.73 & 0.01 & 0.0177 \\
$\mathrm{GF}_{2}$ & 1966.56 & 9.48 & 2.72 & - \\
$\mathrm{GF}_{3}$ & 0.03 & 7.20 & 7.24 & - \\
\hline
\end{tabular}

Table 2. Estimated rate constants for Eqs. (4)

\begin{tabular}{lcccc}
\hline $\mathrm{A}$ & $\mathrm{B}$ & $V_{\mathrm{m}}\left(\mu \mathrm{mol} \mathrm{L} \mathrm{min}^{-1}\right)$ & $K_{\mathrm{m} 2, \mathrm{~A}-\mathrm{B}}\left(\mathrm{mol} \mathrm{L}^{-1}\right)$ & $K_{\mathrm{m} 2, \mathrm{~B}-\mathrm{A}}\left(\mathrm{mol} \mathrm{L}^{-1}\right)$ \\
\hline $\mathrm{GF}$ & $\mathrm{GF}_{2}$ & 156.38 & 0.00 & 4.05 \\
$\mathrm{GF}$ & $\mathrm{GF}_{3}$ & 9.64 & 4.59 & 3.45 \\
$\mathrm{GF}_{3}$ & $\mathrm{GF}_{3}$ & $10,872.71$ & 8.90 & 7.42 \\
\hline
\end{tabular}

include as much process insight as possible including reasonable bounds of parameter values and a proper data normalization (Gábor and Banga, 2015).

The experimental dataset used for parameter estimation contained 464 observations originating from 6 independent test runs. Fig. 3 illustrates the correlation of measured data with those predicted by the model for all observations.

\section{Catalysis in stirred-tank reactor}

Experimental and estimated progress curves of FOS production in batch reactor are shown in Fig. 4. The model gives an adequate prediction, however, it slightly underestimates concentrations of individual FOS fractions that results in a modest misfit in the total FOS profile. A possible reason for this misfit is that the adopted kinetic model does not account for the

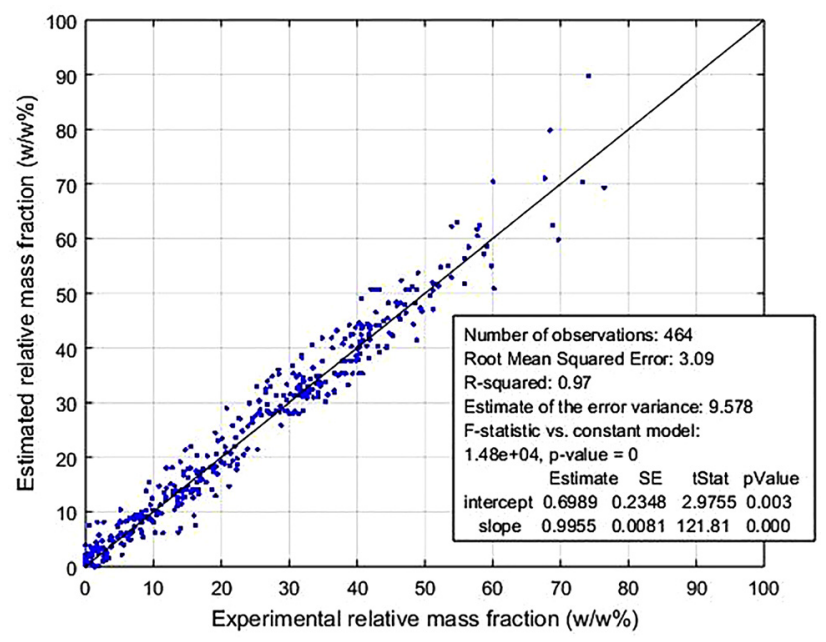

Fig. 3. Estimated versus experimental data 


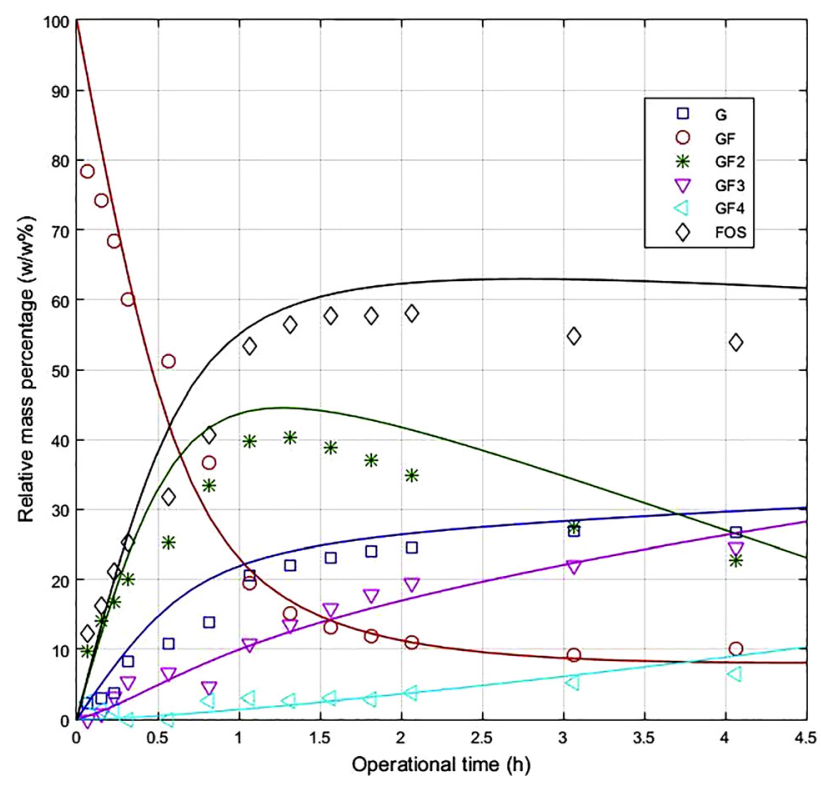

Fig. 4. Time course of fructooligosaccharides synthesis in stirred-tank reactor. Reaction conditions: $50{ }^{\circ} \mathrm{C}$, $40 \mathrm{~g} / 100 \mathrm{~g}$ sucrose, $7.5 \mathrm{~g} / 100 \mathrm{~g}$ crude enzyme dosage, $\mathrm{pH}=5.4$ adjusted by citrate/phosphate buffer. Mean values of duplicate data are shown.

hydrolytic side-activity of the applied enzyme preparation. We note that during the experimental run, the production of small amounts of fructose (up to ca. $6 \mathrm{w} / \mathrm{w} \%$ ) was observed, indicating the hydrolysis of the substrate and/or the generated oligosaccharides.

The sucrose in the reaction liquid is converted into FOS $\left(\mathrm{GF}_{2}, \mathrm{GF}_{3}\right.$, and $\left.\mathrm{GF}_{4}\right)$, glucose, and a small amount of fructose. The relative mass percentage of sucrose decreases from $100 \mathrm{w} / \mathrm{w} \%$ to approx. $11 \mathrm{w} / \mathrm{w} \%$ and that of FOS reaches a plateau at ca. $58 \mathrm{w} / \mathrm{w} \%$ after about $2 \mathrm{~h}$ incubation time. Then, the total amount of FOS remains approximately constant while the composition of short-chain oligosaccharides undergoes further changes during the studied $4 \mathrm{~h}$ reaction. These results are in good agreement with literature data reported for Pectinex Ultra SP-L applying similar reaction conditions (Ghazi et al., 2007; Hang and Woodams, 1996; Nemukula et al., 2009). The resulting productivity of FOS is approx. $1.5 \mathrm{~g}$ per hour and per gram of crude enzyme preparation neglecting the time required for post-treatment of the product liquid. Post-treatment typically includes enzyme deactivation by heat treatment and enzyme removal by additional downstream processing steps. Such activities should be taken into account when estimating productivity and related operational costs of an STR-based process.

\section{Catalysis in enzyme membrane reactor}

Progress curves of FOS production in EMR are shown in Fig. 5.

Three 8 -h process runs were carried out at 1.5 bar (Figs. $5 \mathrm{a}, \mathrm{b}$, and d), and an additional run was conducted for $25 \mathrm{~h}$ at 0.5 bar (Fig. 5(c)). The experiments were performed at various 


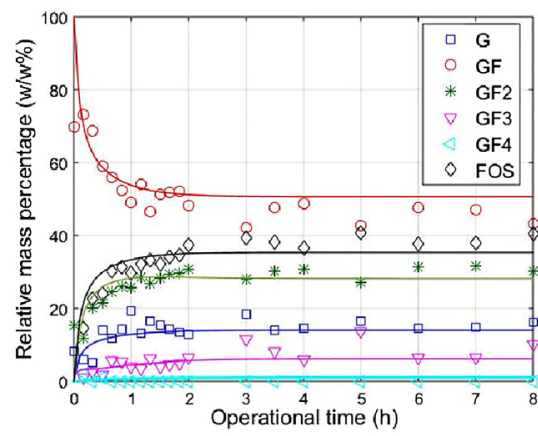

(a) $\tau=36 \mathrm{~min}$

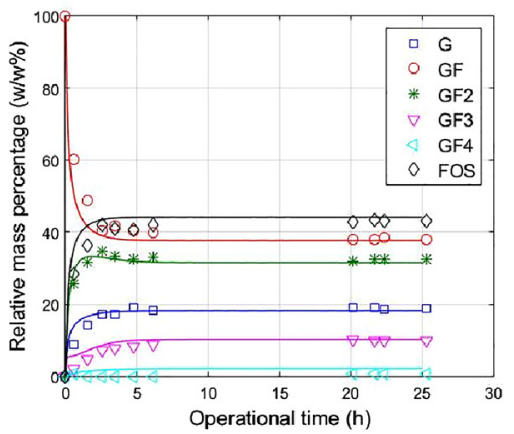

(c) $\tau=66 \mathrm{~min}$

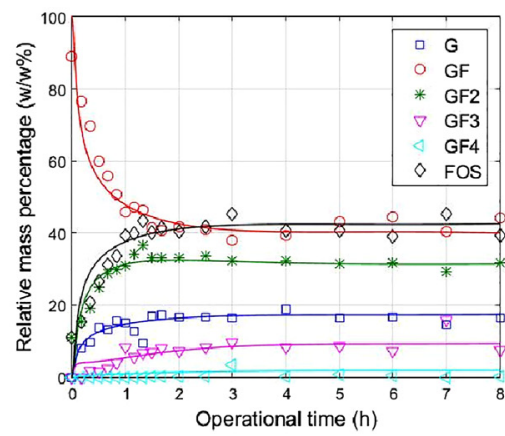

(b) $\tau=59 \mathrm{~min}$

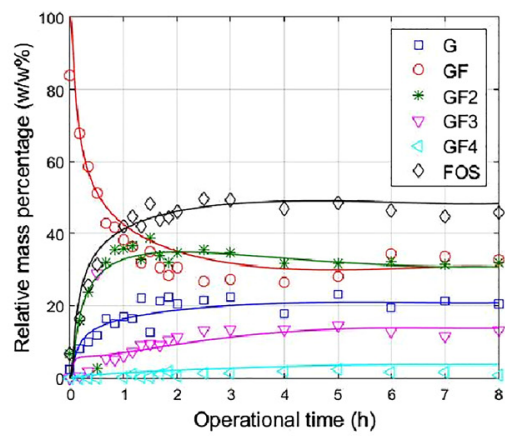

(d) $\tau=102 \mathrm{~min}$

Fig. 5. Saccharides-composition in product stream of EMR as function of processing time at various residence times. Measured and estimated data are illustrated with symbols and continuous lines, respectively. Process conditions: $40 \mathrm{~g} / 100 \mathrm{~g}$ GF in feed, $7.5 \mathrm{~g} / 100 \mathrm{~g}$ crude enzyme dosage, $\mathrm{pH}=5.6,50{ }^{\circ} \mathrm{C}, 20 \mathrm{kDa}$ ceramic UF membrane, $0.5-1.5$ bar, $0.42 \mathrm{~ms}^{-1}$

residence times ranging from 36 to $102 \mathrm{~min}$. The trans-membrane pressure was used to adjust the desired stationary permeate flow-rate. At the initial phase of the filtration, the flux decreased to a certain extent, then it reached a quasi constant value. The indicated residence time was calculated as the ratio of reactor volume to observed stationary permeate flow.

Fig. 5 depicts the dynamics of the transfructosylation reaction. Steady-state was reached typically after ca. $4-5 \mathrm{~h}$, and the EMR shows stable performance with a high level of activity that was maintained over the processing time. Overall, estimated values of carbohydrates are in good agreement with observed data.

Fig. 5(c) shows the composition profile of the product stream of EMR operating for $25 \mathrm{~h}$. During this period of time, no deterioration in the degree of conversion was observed. Operational stability of the enzyme, that is a critical factor often associated with enzymatic reactors, 
Table 3. Steady-state saccharides composition in the permeate of the enzymatic membrane reactor for different residence times compared with the conversion obtained in stirred-tank reactor after $2 \mathrm{~h}$ reaction time. Mean values \pm SEM are listed in $\mathrm{g} / 100 \mathrm{~g}$. Precision given overall as $\sigma_{m}=\sqrt{\frac{\sum_{i=1}^{N}\left(x_{i}-x\right)^{2}}{N(N-1)}}, N=8$ for continuous, $N=2$ for batch processes. Reaction and process conditions are described in the text

\begin{tabular}{lcrrrr}
\hline & \multicolumn{4}{c}{ Continuous process } & \\
\cline { 2 - 4 } Component & \multicolumn{1}{c}{$36 \mathrm{~min}$} & \multicolumn{1}{c}{$59 \mathrm{~min}$} & \multicolumn{1}{c}{$66 \mathrm{~min}$} & \multicolumn{1}{c}{$102 \mathrm{~min}$} & \multirow{2}{*}{ Batch process (at 120 min) } \\
\cline { 2 - 4 } $\mathrm{GF}$ & $45.9 \pm 1.0$ & $41.5 \pm 0.8$ & $38.4 \pm 1.1$ & $30.0 \pm 1.1$ & $11.0 \pm 0.5$ \\
$\mathrm{G}$ & $15.3 \pm 0.6$ & $16.6 \pm 0.4$ & $18.9 \pm 0.3$ & $20.9 \pm 0.6$ & $24.5 \pm 0.3$ \\
$\mathrm{~F}$ & $0.2 \pm 0.2$ & $0.4 \pm 0.2$ & $0.1 \pm 0.1$ & $1.0 \pm 0.4$ & $6.5 \pm 0.1$ \\
$\mathrm{GF}_{2}$ & $29.9 \pm 0.6$ & $31.8 \pm 0.5$ & $32.5 \pm 0.3$ & $33.0 \pm 0.6$ & $34.9 \pm 0.8$ \\
$\mathrm{GF}_{3}$ & $8.6 \pm 1.0$ & $9.1 \pm 1.0$ & $9.8 \pm 0.8$ & $12.9 \pm 0.4$ & $19.4 \pm 0.5$ \\
$\mathrm{GF}_{4}$ & n.d.* & $0.5 \pm 0.3$ & $0.6 \pm 0.4$ & $1.3 \pm 0.2$ & $3.8 \pm 0.5$ \\
FOS & $38.5 \pm 0.5$ & $41.5 \pm 0.9$ & $42.7 \pm 1.0$ & $47.2 \pm 0.6$ & $58.0 \pm 0.8$ \\
\hline
\end{tabular}

* Under detection limit.

did not limit the catalytic performance of EMR under the selected process conditions. Further research will be directed at investigating enzyme stability under long-term operation $(>100 \mathrm{~h})$.

Table 3 summarizes the experimental data on the saccharides composition of the product stream of EMR operating under steady-state conditions. As indicated in Table 3, the FOS content of the saccharides mixture increases with the applied residence time. There can be observed a tendency in the carbohydrate composition regarding polymerization grade: increasing residence time favors the synthesis of oligosaccharides with higher polymerization degree.

Fig. 6 shows simulated and measured values of productivity and conversion as function of residence time. Estimates were obtained by solving differential equations (Eq. (5)) to compute steady-state behavior. Model estimates appear to fit well to experimental results.

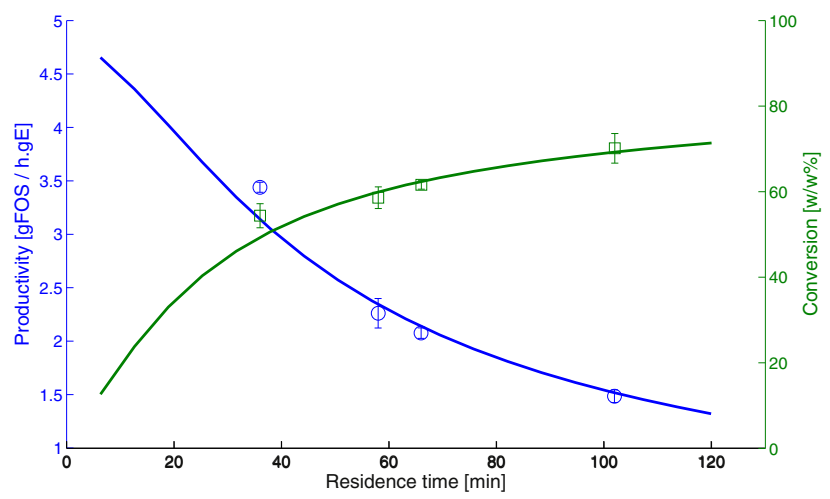

Fig. 6. Productivity $(O)$ and conversion $(\square)$ as a function of residence time. Experimental and estimated values are represented by symbols and solid lines, respectively. (Process conditions: $50{ }^{\circ} \mathrm{C}, 40 \mathrm{~g} / 100 \mathrm{~g}$ GF in feed, $7.5 \mathrm{~g} / 100 \mathrm{~g}$ crude enzyme dosage, $\mathrm{pH}=5.6$ adjusted by citrate/phosphate buffer, $1.5 \mathrm{bar}, 0.42 \mathrm{~ms}^{-1}$ cross-flow rate.) 
The conversion is increased from approx. $54-70 \%$ when residence time is increased from 36 $\min$ to $102 \mathrm{~min}$. In contrast, productivity of FOS in the same range of residence time is decreased from approx. $3.4-1.5 \mathrm{~g}$ per hour and per gram of crude enzyme preparation. Although conversion of sucrose was found to be better in STR than in EMR, EMR compares favorably when comparing performances in term of productivity. Moreover, STR requires the inactivation and removal of enzymes from reaction liquid subsequent to the reaction. In contrast, EMR allows the reuse of the biocatalysts that may generate considerable cost savings in FOS production.

\section{CONCLUSIONS}

The production of FOS by the direct application of soluble enzymes was investigated in traditional STR and in EMR setup. The latter process integrates reaction and separation in a single-step by employing an external UF module for the retention and reuse of the catalysts. The degree of conversion of sucrose into FOS was controlled by adjusting the residence time in the EMR. Under the studied operational conditions, the relative mass percentage of FOS to total carbohydrates in the product stream was found to be $38.7 \pm 1.5,41.7 \pm 2.6,42.8 \pm 1.0$, and 47.3 $\pm 1.9 \%(\mathrm{w} / \mathrm{w})$, for the residence time of $0.6,1.0,1.1$, and $1.7 \mathrm{~h}$, respectively. By increasing the residence time, an increase in the substrate conversion from approx. 54\%-70\% and a decline in the productivity from approx. 3.4-1.5 g per hour and per gram of crude enzyme preparation was observed.

A reaction scheme proposed by Nishizawa et al. (2001) was adopted to model transfructosylation reactions in STR and extended to describe performance of EMR. The model with optimized kinetic parameters appeared to be consistent with experimental observations under studied operational settings. Overall, a good agreement is found between the simulated and experimental results.

The EMR is an inexpensive and easily scalable configuration that allows the partial conversion of sucrose to FOS. The reported model-based framework is a useful tool for the feasibility assessment of an EMR producing FOS in a continuous fashion. Although conventional batch reactor outperforms EMR in term of conversion, EMR compares favorably regarding productivity. The on-site industrial implementation of this technology might be attractive for food manufacturers aiming at utilizing a value-added sweetener mixture with prebiotic properties.

\section{ACKNOWLEDGMENTS}

This work was supported by the Hessian Ministry of Education and Art under Grant LOEWE; the János Bolyai Scholarship Programme of the Hungarian Academy of Sciences; the New National Excellence Program of the Ministry of Human Capacities and by the European Union and co-financed by the European Social Fund (grant agreement no. EFOP-3.6.3-VEKOP-162017-00005); the Slovak Research and Development Agency under Grant APVV 15-0007; and the Scientific Grant Agency of the Slovak Republic under Grant 1/0004/17. 


\section{SYMBOLS}

C Conversion $\left(\mathrm{gg}^{-1}\right)$

$\mathrm{K}_{\mathrm{i}, \mathrm{n}} \quad$ Non-competitive inhibitory constant $\left(\mathrm{molm}^{-3}\right)$

$\mathrm{K}_{\mathrm{m}} \quad$ Dissociation constants $\left(\mathrm{molm}^{-3}\right)$

$\mathrm{P} \quad$ Productivity $\left(\mathrm{gh}^{-1} \mathrm{~g}^{-1}\right)$

$\mathrm{R} \quad$ Reaction rate $\left(\mathrm{molm}^{-3} \mathrm{~s}^{-1}\right)$

$\mathrm{S} \quad$ Concentration of sucrose in feed $\left(\mathrm{molm}^{-3}\right)$

$\mathrm{V}_{\mathrm{m}} \quad$ Maximum transfructosylation rates $\left(\mathrm{molm}^{-3} \mathrm{~s}^{-1}\right)$

$\mathrm{T} \quad$ Operational time (s)

\section{GREEK SYMBOLS}

$\tau \quad$ Residence time (s)

\section{ABBREVIATIONS}

$\begin{array}{ll}\text { E } & \text { enzyme } \\ \text { EMR } & \text { enzymatic membrane reactor } \\ \text { F } & \text { fructose } \\ \text { FOS } & \text { fructooligosacharides } \\ \text { FTase } & \text { fructosyltransferase } \\ \text { G } & \text { glucose } \\ \text { GF } & \text { saccharose } \\ \mathrm{GF}_{2} & \text { 1-kestose } \\ \mathrm{GF}_{3} & \text { nystose } \\ \mathrm{GF}_{4} & 1^{\mathrm{F}} \text {-fructofuranosylnystose } \\ \text { STR } & \text { stirred-tank reactor } \\ \mathrm{UF} & \text { ultrafiltration }\end{array}$

\section{REFERENCES}

Alvarado, M. and Maugeri, F. (2007). Kinetic modelling of fructooligosaccharide synthesis using a rhodotorula sp. fructosyltransferase. Journal of Biotechnology, 131 (Suppl. 2): S91-S92. (\{ECB1313th\} European Congress on Biotechnology).

Burghardt, J.P., Coletta, L.A., van der Bolt, R., Ebrahimi, M., Gerlach, D., and Czermak, P. (2019). Development and characterization of an enzyme membrane reactor for fructo-oligosaccharide production. Membranes, 9: 148.

Chen, S.-C., Sheu, D.-C., and Duan, K.-J. (2014). Production of fructooligosaccharides using $\beta$-fructofuranosidase immobilized onto chitosan-coated magnetic nanoparticles. Journal of the Taiwan Institute of Chemical Engineers, 45(4): 1105-1110. 
Draper, N.R. and Smith, H. (2014). Applied regression analysis. Wiley.

Duan, K.J., Chen, J.S., and Sheu, D.C. (1994). Kinetic studies and mathematical model for enzymatic production of fructooligosaccharides from sucrose. Enzyme and Microbial Technology, 16 (4): 334-339.

Erdős, B., Grachten, M., Czermak, P., and Kovács, Z. (2018). Artificial neural network-assisted spectrophotometric method for monitoring fructo-oligosaccharides production. Food and Bioprocess Technology, 11(2): 305-313.

Gábor, A. and Banga, J.R. (2015). Robust and efficient parameter estimation in dynamic models of biological systems. BMC Systems Biology, 9(1): 74.

Ghazi, I., Fernandez-Arrojo, L., Garcia-Arellano, H., Ferrer, M., Ballesteros, A., and Plou, F.J. (2007). Purification and kinetic characterization of a fructosyltransferase from Aspergillus aculeatus. Journal of Biotechnology, 128 (1): 204-211.

Ghazi, I., Fernandez-Arrojo, L., Gomez De Segura, A., Alcalde, M., Plou, F.J., and Ballesteros, A. (2006). Beet sugar syrup and molasses as low-cost feedstock for the enzymatic production of fructo-oligosaccharides. Journal of Agricultural and Food Chemistry, 54 (8): 2964-2968.

Guio, F., Rugeles, L.D., Rojas, S.E., Palomino, M.P., Camargo, M.C., and Sánchez, O.F. (2012). Kinetic modeling of fructooligosaccharide production using aspergillus oryzae n74. Applied Biochemistry and Biotechnology, 167(1): 142-163.

Hang, Y. and Woodams, E. (1996). Optimization of enzymatic production of fructo-oligosaccharides from sucrose. LWT - Food Science and Technology, 29 (56): 578 - 580.

Hindmarsh, A.C., Brown, P.N., Grant, K.E., Lee, S.L., Serban, R., Shumaker, D.E., and Woodward, C.S. (2005). SUNDIALS: Suite of nonlinear and differential/algebraic equation solvers. ACM Transactions on Mathematical Software (TOMS), 31(3): 363-396.

Jung, K.H., Yun, J.W., Kang, K.R., Lim, J.Y., and Lee, J.H. (1989). Mathematical model for enzymatic production of fructo-oligosaccharides from sucrose. Enzyme and Microbial Technology, 11(8): 491-494.

Kashyap, R., Palai, T., and Bhattacharya, P.K. (2015). Kinetics and model development for enzymatic synthesis of fructo-oligosaccharides using fructosyltransferase. Bioprocess and Biosystems Engineering, 38(12): 2417-2426.

Khandekar, D.C., Palai, T., Agarwal, A., and Bhattacharya, P.K. (2014). Kinetics of sucrose conversion to fructo-oligosaccharides using enzyme (invertase) under free condition. Bioprocess and Biosystems Engineering, 37(12): 2529-2537.

Nemukula, A., Mutanda, T., Wilhelmi, B., and Whiteley, C. (2009). Response surface methodology: Synthesis of short chain fructooligosaccharides with a fructosyltransferase from Aspergillus aculeatus. Bioresource Technology, 100(6): 2040-2045.

Nishizawa, K., Nakajima, M., and Nabetani, H. (2000). A forced-flow membrane reactor for transfructosylation using ceramic membrane. Biotechnology and Bioengineering, 68(1): 92-97.

Nishizawa, K., Nakajima, M., and Nabetani, H. (2001). Kinetic study on transfructosylation by $\beta$-fructofuranosidase from Aspergillus niger ATCC 20611 and availability of a membrane reactor for fructooligosaccharide production. Food Science and Technology Research, 7(1): 39-44.

Picazo, B., Flores-Gallegos, A.C., Muñiz-Márquez, D.B., Flores-Maltos, A., Michel-Michel, M.R., de la Rosa, O., and Aguilar-González, C.N. (2019). Chapter 18 - enzymes for fructooligosaccharides production: Achievements and opportunities. In Kuddus, M. (Ed.), Enzymes in food biotechnology. Academic Press, pp. 303-320.

Rehman, A.U., Kovacs, Z., Quitmann, H., Ebrahimi, M., and Czermak, P. (2016). Enzymatic production of fructooligosaccharides from inexpensive and abundant substrates using a membrane reactor system. Separation Science and Technology, 51(9): 1537-1545. 
Rocha, O., Nobre, C., Dominguez, A., Torres, D., Faria, N., Rodrigues, L., Rocha, I. (2009). A dynamical model for the fermentative production of fructooligosaccharides. In Alves, R., Nascimento, C., and Biscaia, E. (Eds.), 10th International Symposium on Process Systems Engineering: Part A, Vol. 27. Elsevier, pp. 1827-1832.

Sangeetha, P., Ramesh, M., and Prapulla, S. (2005). Recent trends in the microbial production, analysis and application of fructooligosaccharides. Trends in Food Science and Technology, 16(10): 442-457.

Tanriseven, A., and Aslan, Y. (2005). Immobilization of Pectinex Ultra SP-L to produce fructooligosaccharides. Enzyme and Microbial Technology, 36(4): 550-554.

Vega, R., and Zuniga-Hansen, M. (2014). A new mechanism and kinetic model for the enzymatic synthesis of short-chain fructooligosaccharides from sucrose. Biochemical Engineering Journal, 82, 158-165.

Vega-Paulino, R., and Zúniga-Hansen, M. (2012). Potential application of commercial enzyme preparations for industrial production of short-chain fructooligosaccharides. Journal of Molecular Catalysis B: Enzymatic, 76, 44-51.

Yun, J.W. (1996). Fructooligosaccharides - occurrence, preparation, and application. Enzyme and Microbial Technology, 19(2): 107-117.

Open Access. This is an open-access article distributed under the terms of the Creative Commons Attribution 4.0 International License (https://creativecommons.org/licenses/by/4.0/), which permits unrestricted use, distribution, and reproduction in any medium, provided the original author and source are credited, a link to the CC License is provided, and changes - if any - are indicated. (SID_1) 